\title{
Effectiveness of dry needling in equinovarus foot deformity in patients with cerebrovascular accident
}

\author{
Sánchez Milá Z. ${ }^{1}$ López Pascua C. ${ }^{1}$ Ranz Ramírez E. ${ }^{1}$ Castrillo Calvillo A. ${ }^{1}$ \\ ${ }^{1}$ Centro de rehabilitación neurológica LESCER, Madrid, Spain \\ Rev Fisioter Invasiva 2019;2:102.
}

\begin{abstract}
Keywords

- Spasticity

- cerebrovascular accident

- dry needling

Introduction Spasticity secondary to cerebrovascular accident is one of the main causes of disability in adults. Equinovarus foot is a common condition in patients with cerebrovascular accident, with an estimated prevalence of $18 \%$ (Verdié C. 2004). This deformity is mainly caused by spasticity of the tibialis posterior muscle, together with weakness of the tibialis anterior.

Aims To determine the effects of deep dry needling together with neurorehabilitation treatment (based on the Bobath concept) on spasticity and motor function after a cerebrovascular accident.

Material and Methods A single-blinded randomized experimental study, which comprised ten $(n=10)$ patients who had suffered a cerebrovascular accident, who were randomly assigned to a control group (CG) who received neurorehabilitation treatment $(n=5)$ and another experimental group (EG) who received ultrasoundguided dry needling in the tibialis posterior and tibialis anterior muscles plus neurorehabilitation treatment $(n=5)$. Measurements were made at baseline and ten minutes after treatment by a blinded evaluator who measured spasticity (Ashworth scale) and motor function (timed up and go test).

Results The subjects who received dry needling showed a decrease in spasticity after treatment of the tibialis posterior $(\mathrm{P}<0.001)$ and the tibialis anterior muscles $(\mathrm{P}<0.003)$ compared to those who did not receive treatment. The descriptive analysis of the timed up and go test, (CG pre:22.7720/post:21.8060 and EG pre:23.8960/ post: $17.9780^{*}$ ) revealed a decrease in times for both groups, which was more significant in the group of neurorehabilitation treatment plus dry needling.

Conclusion The inclusion of deep dry needling in a session of neurorehabilitation treatment (following the Bobath concept) appears to be effective for the normalization of tone and for the improvement of balance during the gait cycle in patients who have suffered a cerebrovascular accident.
\end{abstract}

DOI https://doi.org/
Copyright $\odot 2019$ by Thieme Revinter

Publicações Ltda, Rio de Janeiro, Brazil
License terms 